\title{
An Online Solid Phase Extraction-Liquid Chromatography Tandem Mass Spectrometry Method for the Analysis of Parabens in Urban Waters
}

\author{
Simone Nascimento ${ }^{\circledR a}$ and Quezia Cass $^{\oplus *, b}$ \\ ${ }^{a}$ Agilent Brasil, Alameda Araguaia, 1142, 06455-000 Barueri-SP, Brazil \\ ${ }^{b}$ Departamento de Química, Universidade Federal de São Carlos, \\ Rodovia Washington Luís, km 235, 13565-905 São Carlos-SP, Brazil
}

\begin{abstract}
In this work, we report a method to quantify methylparaben, ethylparaben, propylparaben and butylparaben in urban waters of São Carlos (São Paulo State, Brazil) by online solid phase extraction-liquid chromatography tandem mass spectrometry (SPE-LC-MS/MS) system. The method achieved ng $\mathrm{L}^{-1}$ limits with good accuracy and precision (internal standards for each paraben were used). The total run cycle time takes 9.5 min per sample including the extraction, cleanup and columns conditioning cycles, lower collection volumes of urban water and solvent usage. The SPE cartridge applied showed robustness allowing over 500 sample injections ( $800 \mu \mathrm{L}$ each) with good chromatographic performance. This study findings included the detection of parabens in samples in São Carlos.
\end{abstract}

Keywords: sample cleanup, antimicrobials, personal care, SPE-LC-MS/MS

\section{Introduction}

Parabens are a group of substances used for more than 100 years as a preservative antimicrobials in cosmetics, food and pharmaceuticals and have been detected frequently in aquatic and biological environments. ${ }^{1-19}$ The parabens commonly found in cosmetics are: methylparaben (MP), ethylparaben (EP), propylparaben (PP) and butylparaben (BP). ${ }^{10-17}$ Commercially, parabens are produced by esterification of the $p$-hydroxybenzoic acid associated to alcohol in the presence of a catalyst (for example, concentrated sulfuric acid or $p$-toluenesulfonic acid). ${ }^{1,2,15}$

They have many advantages compared to other preservatives, such as stability and efficiency over a wide $\mathrm{pH}$ range, in addition to using water-soluble substances, they have no noticeable odor or taste, they do not affect color and are stable. Accepting these characteristics, parabens can be used effectively in personal care products, as preservatives even in the water phase and are also used as additives in food packaging. ${ }^{10-15}$ The antibacterial properties of parabens are directly proportional to the length of the ester group chain, and so, for example, butylparaben is 4 times more capable of inhibiting the bacterial growth than

*e-mail: qcass@ufscar.br ethyl paraben. The increases on the length of the chain, however, rises partition coefficient problems resulting in lower water solubility. ${ }^{11,12}$

Approximately $80 \%$ of personal care products contain parabens. ${ }^{12-15}$ In chlorinated waters, phenolic compounds containing hydroxyl groups such as parabens have favorable kinetics for chlorination, thus they are easily chlorinated by sodium hypochlorite, which is one of the most used techniques for water bleaching., $212,14,15$

Parabens have been detected in effluents at concentrations up to $13 \mu \mathrm{g} \mathrm{L^{-1 }}$, this shows that daily pharmaceutical and personal care products are continuously released into aquatic environments. ${ }^{6,7}$

Other studies ${ }^{2-6}$ indicate that bioaccumulation of parabens can occur in the environment. Results presented in scientific articles ${ }^{3-5}$ mention that human exposure daily is up to $8 \mu \mathrm{g} \mathrm{kg}^{-1}$ from personal care products, $417 \mu \mathrm{g} \mathrm{kg}^{-1}$ from pharmaceutical products, $0.00253 \mu \mathrm{g} \mathrm{kg}^{-1}$ from food products, among other contacts coming from dust and air. The pathway of this human exposure is domestic sewage. Studies $^{2-6}$ have shown the concentration in influent of

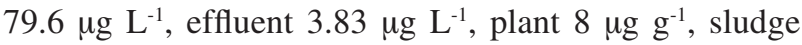
$0.202 \mu \mathrm{g} \mathrm{g}^{-1}$, soil $0.008 \mu \mathrm{g} \mathrm{g}^{-1}$, sediment $0.377 \mu \mathrm{g} \mathrm{g}^{-1}$, surface waters $3 \mu \mathrm{g} \mathrm{L}^{-1}$ and in fish $3.6 \mu \mathrm{g} \mathrm{g}^{-1}$.

The analytical method for determining drug/pollutants traces in complex environmental matrices involves a 
considerable number of methods already described in the literature, ${ }^{20-22}$ and this number has increased considerably. More than twenty years ago, gas chromatography technique coupled with mass spectrometry (GC-MS) and extraction of compounds using $1 \mathrm{~L}$ of samples and in some cases derivatization were the most used approach to quantify small organic molecules in low concentrations, such as $\mu \mathrm{g} \mathrm{L}^{-1}$ and $\mathrm{ng} \mathrm{L}^{-1} .23-28$

Sample collection, storage and preservation, transport and pre-treatment steps are as important as the type of sample preparation selected to guarantee the quality of the results, ${ }^{29-32}$ but higher volumes of water as $0.1-1 \mathrm{~L}$ involve larger rooms to process the samples, larger amount of extraction solvents and more sample preparation time.

Studie ${ }^{29,30}$ show that the time and labor intensity spent on sample preparation remains responsible for nearly $70 \%$ of the total time in the laboratory to achieve lower limit of quantification. The time spent in most cases involves time-consuming steps. For this reason, and with the increasing number of samples to be analyzed in monitoring laboratories, there is a continuous search for methods of high productivity, cost effective and easy handling. With this, there has been an increase in the use of automated instruments that integrate extraction, purification and detection. ${ }^{33-36}$ Also, surveys ${ }^{29,30}$ indicate that sample loads and sample per week will increase in the next years, which means the need of faster sample preparation and chromatography methods.

Generic approaches have been developed to prepare water samples with the final analysis by LC-MS/MS (liquid chromatography coupled with sequential mass spectrometry) mainly involving techniques such as: LLE (liquid-liquid extraction), SPE (solid phase extraction), QuEChERS (quick, easy, cheap, effective, rugged, and safe), SPME (solid phase microextraction) and SBSE (stir bar sorptive extraction), yet other techniques such as: RAM (restricted access materials) and TFC (turbulent flow chromatography) have been explored. ${ }^{28-45}$

Currently, LC-MS/MS offers high sensitivity, ${ }^{29,40}$ uses smaller sample volumes, allows lower transportation and storage prices, reduces the possibility of handling error, employs less amount of solvent providing double benefits by less acquisition and disposal cost, no evaporation step decreasing time-consuming and an integrated system of software rising productivity.

The SPE technique basically consists of four stages: (i) conditioning, to activate the silica-based materials avoiding hydrophobic-hydrophilic shielding and/or to ensure the cleaning of the polymer-based materials, (ii) loading of the sample for the extraction/enrichment of the analytes of interest, (iii) cleanup for purification of the SPE phase, since many interferents are extracted with the target compounds and (iv) elution to obtain the analyte. ${ }^{29,30,34-36}$

Silica-based phases materials due to their diversity have shown to be able to extract a variety classes of analytes. The most used in aqueous matrices has being the $\mathrm{C} 18$ type derivative, other types are also used such as $\mathrm{C} 8$, phenyl, $\mathrm{NH} 2$, SAX (strong anion exchange) and SCX (strong cation exchange), however, silica-based phases have limitations due to the narrow operating $\mathrm{pH}$ range. Thus, polymeric phases have been gaining popularity since they have similar $\mathrm{C} 18$ and weak ion exchange types selectivity, but high $\mathrm{pH}$ range applications. ${ }^{35-42,46}$

The online mode presents as main advantages reusable column type cartridges, fast elution with less solvent consumption, minimal degradation and no loss of analyte by evaporation resulting in reduced analysis time. The disadvantages are fewer material phases availability and lower analyte concentration factor. ${ }^{46-50}$

The term online SPE applies when switching valves are used to couple the SPE column to the analytical column. The chromatographic system can be configured with high flexibility on. The most selected are the 10-port system that present the same functionality as the 6-port valve but has the advantage of working with two SPE columns at the same time with higher-throughput. ${ }^{51,52}$

Applications of online SPE systems have become increasingly popular and different types of applications have been published such as drugs, carbamates, pyrethroids, sulfonamides and pharmaceuticals in water. The common injection volumes usually are $0.5 \mathrm{~mL}$ up to $10 \mathrm{~mL} .^{52-57}$

This study aimed to investigate the occurrence of parabens in urban water and herein we report a qualified online SPE-LC-MS/MS method at ng L $\mathrm{L}^{-1}$ limits. The results presented herein might be useful to support new researches on analysis of water contaminants with greener methods.

\section{Experimental}

\section{Standards, materials and reagents}

For the experiments, standards of target compounds were acquired from Sigma-Aldrich (Saint Louis, USA) including $1 \mathrm{~g}$ per flask of methylparaben (MP) part number PHR1012-1G, ethylparaben (EP) part number PHR1011-1G, propylparaben (PP) part number PHR1010-1G and butylparaben (BP) part number PHR1022-1G, and a mixture of internal standard (IS) at $10 \mathrm{mg} \mathrm{L}^{-1}$ in acetone of each paraben represented as ${ }_{13} \mathrm{C}^{6}$ part number 32124-5ML. A fulvic acid solution IHSS SUWANNE batch 1S101 was donated by Analytical Instrumentation laboratory 
of Embrapa (São Carlos, Brazil) and humic acid of the Sigma-Aldrich (Saint Louis, USA) part number 53680 was donated by the Environmental Biogeochemistry Laboratory of UFSCar (São Carlos, Brazil).

Regenerated cellulose membrane Agilent (Santa Clara, USA) part number 5190-5109 $(15 \mathrm{~mm} \times 0.45 \mu \mathrm{m})$ were used for sample filtration, and Agilent $2 \mathrm{~mL}$ vials, pre-slit septa and screw caps (part number 5183-2076 and 5182-0715) were also used. A polymeric reversed phase for small molecules sorbent that is hydrophobic, with no bonded phase or alkyl ligands, Agilent PLRP-S $(2.1 \times 12.5 \mathrm{~mm}, 15 \mu \mathrm{m})$ were used as the online SPE cartridge while the analytical column was the Poroshell SB-C18 column $(2.1 \times 50 \mathrm{~mm}, 2.7 \mu \mathrm{m})$.

The solvents methanol and acetonitrile were LC-MS grade from Sigma-Aldrich or Honeywell (Charlotte, USA) and ultra-pure water from a Sartorius (Göttingen, Germany) system. Otherwise stated, the mobile phases were prepared as $\mathrm{v} / \mathrm{v}$ relationship.

Site of sample collection and pre-treatment

Water samples were collected at discharge along the Monjolinho River in the region of São Carlos, SP, Brazil in November 2016. The location of samples sites are: (1) Monjolinho spring water: latitude $22^{\circ} 00^{\prime} 33^{\prime \prime} \mathrm{S}$ and longitude $47^{\circ} 50^{\prime} 07^{\prime \prime} \mathrm{W}$ and presented $\mathrm{pH} 7$; (2) areas with possible industrial and urban contamination: latitude $21^{\circ} 98^{\prime} 58^{\prime} \mathrm{S}$, longitude $47^{\circ} 88^{\prime} 22^{\prime} \mathrm{W}$ and presented $\mathrm{pH} 7.5$, it is located at the Federal University of São Carlos (UFSCar); (3) close to the confluence with the Tijuco Preto stream, inserted in an urbanized area latitude $22^{\circ} 00^{\prime} 68^{\prime \prime} \mathrm{S}$, longitude $47^{\circ} 90^{\prime} 47^{\prime \prime} \mathrm{W}$ and presented $\mathrm{pH} 7.5$ and (4) is after an urban area, latitude $22^{\circ} 02^{\prime} 21^{\prime \prime} \mathrm{S}$, longitude $47^{\circ} 91^{\prime} 40^{\prime \prime} \mathrm{W}$ and presented $\mathrm{pH}$ 7.5. The sewage treatment system in the city of São Carlos is operational at $100 \%$, currently. Samples were transported to the laboratory, and to remove suspended particles they were filtered through regenerated cellulose membrane before being stored at $4{ }^{\circ} \mathrm{C}$ if not instantly analyzed after preparation.

\section{Working solutions}

Individual solutions of target parabens were prepared in the following concentrations: $280 \mathrm{mg} \mathrm{L}^{-1} \mathrm{MP}, 740 \mathrm{mg} \mathrm{L}^{-1} \mathrm{EP}$, $1,050 \mathrm{mg} \mathrm{L}^{-1} \mathrm{PP}$ and $1,020 \mathrm{mg} \mathrm{L}^{-1} \mathrm{BP}$. The preparation was carried out by dissolving $2.8 \mathrm{mg}$ of MP, $7.4 \mathrm{mg}$ of EP, $10.5 \mathrm{mg}$ of PP and $10.2 \mathrm{mg}$ of BP in $10 \mathrm{~mL}$ of solvent mixture of methanol and water (50:50). Thus, a solution of the mixture of parabens at $10 \mathrm{mg} \mathrm{L}^{-1}$ in water and methanol (95:5) was finally prepared.
A methanolic solution containing the four $\left({ }_{13} \mathrm{C}^{6}\right)$ internal standards at $10 \mu \mathrm{g} \mathrm{L}{ }^{-1}$ was prepared to be added to the blank and water samples, and calibration solutions.

\section{Calibration curve, quality controls and samples analysis}

The paraben mixture solution at $10,000,000 \mathrm{ng} \mathrm{L}^{-1}$ was diluted in analyte-free spring water from Monjolinho River to produce the working solution at $1,000 \mathrm{ng} \mathrm{L}^{-1}$ from which the calibrators were prepared at the following concentrations: $3.9,7.8,15.6,31.25,62.5,125,250,500$ and $1000 \mathrm{ng} \mathrm{L}^{-1}$. The quality controls (QCs) solutions evaluated were also prepared on an analyte-free spring water in the following concentrations $20,400,800 \mathrm{ng} \mathrm{L}^{-1}$ for MP and PP, 90, 400, $800 \mathrm{ng} \mathrm{L}^{-1}$ for EP and 10, 400, $800 \mathrm{ng} \mathrm{L}^{-1}$ for BP. A $5.0 \mu \mathrm{L}$ solution of IS at 10,000 $\mathrm{ng} \mathrm{L}^{-1}$ was added to each $1 \mathrm{~mL}$ of blanks, QCs, water samples and calibrators, corresponding to $50 \mathrm{ng} \mathrm{L}^{-1}$ of deuterated standard at final concentration.

\section{Online SPE-LC-MS/MS method}

The SPE-LC-MS/MS system was from Agilent and composed by an autosampler, an online SPE unit, and an ultra high pressure liquid chromatography (UHPLC) 1290 with a MS/MS 6460C model having an electrospray ionization source with jet stream technology (ESI-AJS). The MassHunter acquisition, qualitative, quantitative and optimizer software was used for data analysis..$^{58}$

The samples load injections were of $800 \mu \mathrm{L}$ at a flow rate of $900 \mu \mathrm{L}$ per min. Then, a mixture of water: methanol (95:5) flushed the PLRP-S cartridges at $1 \mathrm{~mL} \mathrm{~min}^{-1}$ by $90 \mathrm{~s}$ to polar interferents removal (Figure 1a). For the analysis, the valve position was changed to connect the SPE cartridge to the Poroshell SB-C18 analytical column set at the UHPLC system (Figure 1b). Gradient elution with water (A) and acetonitrile (B) without any additives were used at the following conditions: $5 \%$ of $\mathrm{B}$ held on $1.76 \mathrm{~min}$ to $67 \%$ of B at $5.86 \mathrm{~min}$ and finally $100 \%$ of B at $6.26 \mathrm{~min}$ held until 8 min at $0.4 \mathrm{~mL} \mathrm{~min}^{-1}$. Oven temperature at $50{ }^{\circ} \mathrm{C}$ and MS/MS were used while one SPE cartridge were in running analyses, simultaneously the valve configuration allowed the second cartridge to be prepared for the next load injection. For that, methanol at $1 \mathrm{~mL} \mathrm{~min}{ }^{-1}$ for $200 \mathrm{~s}$ was used aiming to fasten cleanup cartridge and minimizing the carryover, then, the conditioning solution of water: methanol (95:5) at $1 \mathrm{~mL}$ per min for $230 \mathrm{~s}$ was applied allowing the cartridge to be ready for the next analysis. The total run of analysis time was $9.5 \mathrm{~min}$ per sample.

The conditions used for ESI-AJS in negative mode were gas temperature at $300{ }^{\circ} \mathrm{C}$, gas flow at $10 \mathrm{~L} \mathrm{~min}^{-1}$, nebulizer 

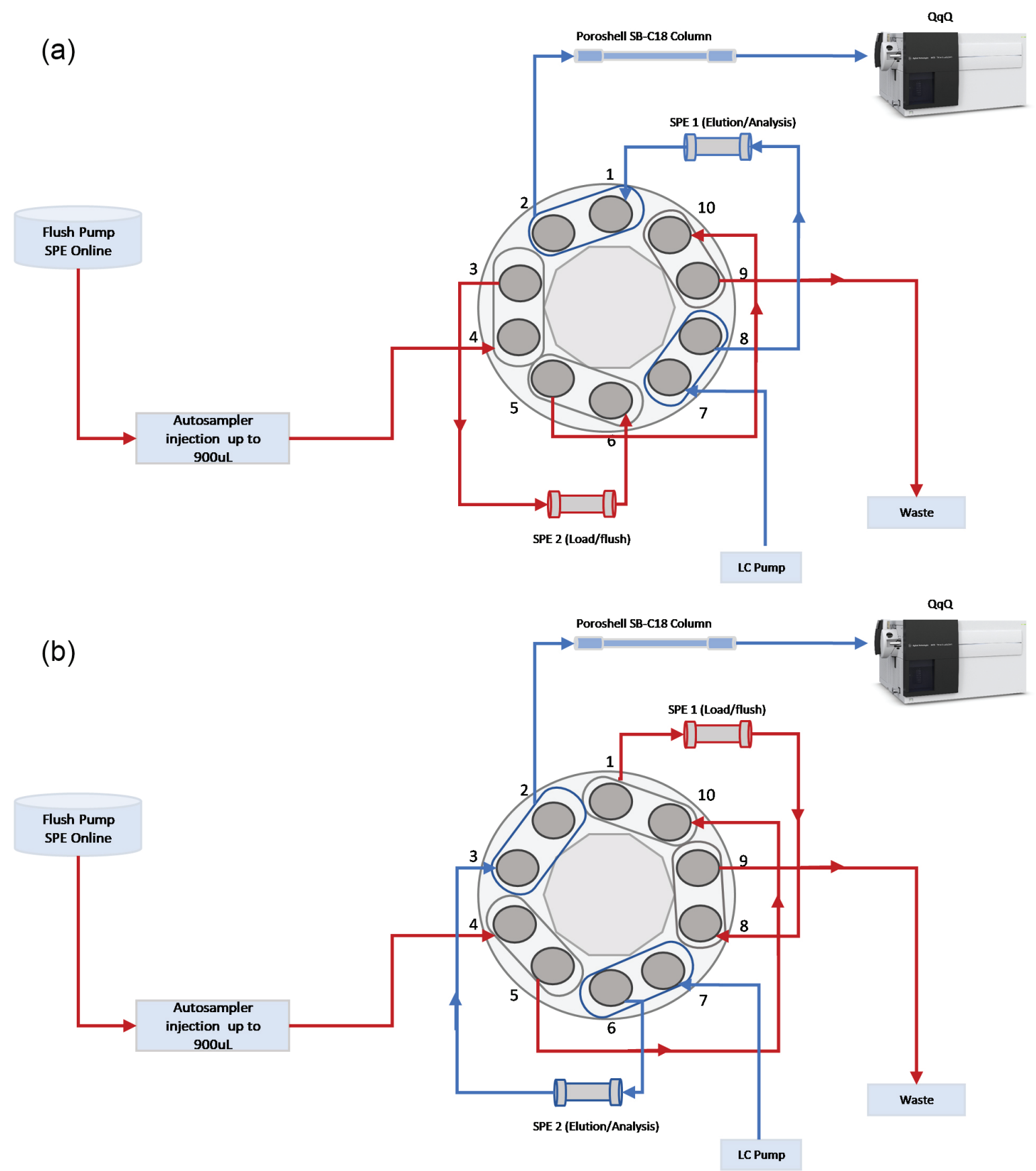

Figure 1. (a) Online SPE system at position 1 with 10-port valve with two available positions; (b) online SPE system at position 2 with a 10-port valve with two available positions.

at $50 \mathrm{psi}$, heat sheath gas temperature at $350{ }^{\circ} \mathrm{C}$, sheath gas flow at $11 \mathrm{~L} \mathrm{~min}^{-1}$, capillary $3500 \mathrm{~V}$, nozzle voltage $500 \mathrm{~V}$ and cell accelerator at $7 \mathrm{~V}$. The SRM (selected reaction monitoring) for target analytes were MP $151>92$ (collision energy (CE) $16 \mathrm{~V}), 151>136(\mathrm{CE} 8 \mathrm{~V})$ and $85 \mathrm{~V}$ for fragmentor, EP 165 > 92 (CE 16 V), $165>137$ (CE 8 V) and $65 \mathrm{~V}$ for fragmentor, PP $179>192(\mathrm{CE} 20 \mathrm{~V}), 179>137$ $(\mathrm{CE} 7 \mathrm{~V})$ and $80 \mathrm{~V}$ for fragmentor, BP $193>92(\mathrm{CE} 20 \mathrm{~V})$, $193>136(\mathrm{CE} 23 \mathrm{~V})$ and $60 \mathrm{~V}$ for fragmentor. The SRM for internal standards were $\mathrm{MP}{ }^{13} \mathrm{C}_{6} 157>98(\mathrm{CE} 16 \mathrm{~V})$,
$\mathrm{EP}^{13} \mathrm{C}_{6} 171>98(\mathrm{CE} 18 \mathrm{~V}), \mathrm{PP}^{13} \mathrm{C}_{6} 185>98$ (CE $\left.20 \mathrm{~V}\right)$, $\mathrm{BP}{ }^{13} \mathrm{C}_{6} 199>98$ (CE $20 \mathrm{~V}$ ) and fragmentor voltage were the same as target analytes, respectively.

\section{Matrix effect procedure and method validation}

The qualification protocol of the method was based on the bioanalytical validation guide EMA (European Medicines Agency) $)^{59}$ and following parameters were evaluated: memory effect, calibration curve, selectivity, 
recovery (extraction efficiency), precision and accuracy, limits of quantification and detection, dilution integrity, matrix effect and stability.

The evaluation of matrix effect (ME) was determined by calculating the peak area of internal standards compounds in spiked samples with the lowest and highest QCs from sites samples 2, 3 and 4, and then, the percentage of increase/decrease of signals in different lots of spring water samples (site 1) were calculated. Subsequently, for the investigation of ME, an injection of samples (2, 3 and 4) and standards solutions at $14.5 \mathrm{mg} \mathrm{L}^{-1}$ of fulvic acids and $2.9 \mathrm{mg} \mathrm{L}^{-1}$ humic acids prepared in ultra-purified water were analyzed by the same online SPE and UHPLC method conditions for target analytes, however, coupling to diode array detector (Agilent 1290 model) at $254 \mathrm{~nm}$ with the MS/MS valve on waste position.

The chemical stability of parabens was evaluated by the results of solution prepared at $125 \mathrm{ng} \mathrm{L}^{-1}$ in ultra-pure water and QCs of spiked sample 4 at low and high concentration at room temperature and injected as freshly prepared, after $4 \mathrm{~h}, 24 \mathrm{~h}$ (autosampler stability) and finally after 8 days of refrigeration at $4{ }^{\circ} \mathrm{C}$.

To determine linearity, six blank spring water samples were spiked in triplicate at six different concentration level and external calibration curve was constructed by plotting the peak area versus concentration and internal standard. For selectivity evaluation, collected analytefree spring water samples were compared with spring water samples spiked with the mixture of the parabens at LOQ (limit of quantification) concentration. Samples were individually analyzed and evaluated for interference. Precision was expressed as relative standard deviation (RSD) of the replicate measurements and the accuracy of the method was evaluated as the percentage between the calculated and the nominal concentration of each analyte. The extraction efficiencies were calculated using the QC samples. The percentage of recovery was obtained comparing the processes data of QC samples with those prepared at the same concentration in ultrapure water. The LOQ values were determined using spiked spring water samples prepared in triplicate. The LOD (limit of detection) was calculated as the minimum detectable amount of compound, with a signal-to-noise $(\mathrm{S} / \mathrm{N})$ ratio of $\geq$ three. The LOQ was obtained as the lowest calibration level with the accepted criteria that the precision and the accuracy for three extracted samples had variability of less or equal to $20 \%$. In accordance with EMA protocol, the obtained RSD were under $15 \%$ variability.

\section{Results and Discussion}

Online SPE systems as illustrated in Figures 1a and $1 \mathrm{~b}$ have demonstrated to be an asset for environmental laboratories as it requires minimal time pre-treatment, sample preparation and, thereby increases throughput. Moreover, it reduces total volume of collected samples succeeding in requiring less storage space in a cooling chamber or refrigerator. ${ }^{33-40}$

For setting up the online SPE system, a sequence of events must be carefully examined. This involves the steps illustrated at Figure 2: $(i)$ analytes ionization, including the selection of ionization mode, collision energy and capillary voltage; (ii) selection of mobile phases that involves experiments with different solvents, flow rate and additives within the analytical column with/without coupling to the SPE column; (iii) the final adjustment of the ionization source parameters involving temperature, nebulizing flow, sheath and drying gas, and finally, (iv) selection of suitable solvents for the conditioning of cartridge and cleanup of interferences from the samples via online SPE.

The four steps $(i-i v)$ designed in flow chart (Figure 2) were followed. In this respect, evaluation of the ionization conditions of the analytes on positive and negative ionization modes were the first parameters selected $(i)$.

\begin{tabular}{|c|c|c|c|}
\hline $\begin{array}{l}\text { (i) Optimization } \\
\text { of analytes } \\
\text { ionization }\end{array}$ & $\begin{array}{l}\text { (ii) LC } \\
\text { conditions }\end{array}$ & $\begin{array}{l}\text { (iii) Final } \\
\text { optimization of } \\
\text { MS source }\end{array}$ & $\begin{array}{l}\text { (iv) Online SPE } \\
\text { cartriged } \\
\text { adjustments }\end{array}$ \\
\hline $\begin{array}{l}\text { Evaluation: } \\
\text { •MS/MS } \\
\text { •Flow injection } \\
\text { analysis (FIA) }\end{array}$ & $\begin{array}{l}\text { Evaluation: } \\
\text { - LC mobile } \\
\text { phase selection } \\
\text { - LC column } \\
\text { phase selection } \\
\text {-Flow }\end{array}$ & $\begin{array}{l}\text { Evaluation: } \\
\bullet \text { MS source } \\
\text { conditions } \\
\text { ESI-AJS } \\
\text { •LC-MS/MS }\end{array}$ & $\begin{array}{l}\text { Evaluation: } \\
\text { - Conditioning } \\
\text { - Additional } \\
\text { cleanup } \\
\text { conditions } \\
\text {-Final SPE-LC- } \\
\text { MS/MS method }\end{array}$ \\
\hline
\end{tabular}

Figure 2. Sequence of events for method development and optimization followed by first $(i)$ upper analytes ionization and SRM transitions by direct injection, (ii) selection of mobile phase for sensitivity and separation enhancement, (iii) evaluation of source optimization in equilibrium with previous steps and finally $(i v)$ adjustments of online SPE steps. 
The highest signal intensities were obtained at the negative polarity mode, and thus selected for the experiments. The parameters were adjusted by the Optimizer software for SRM for each paraben..$^{58}$ By optimization of the fragmentor voltage $(\mathrm{V})$ for each ion, selection of the product ions and $\mathrm{CE}$ values of each transition were carried out for selecting the quantification and qualification ion transitions. The standard conditions ESI-AJS source for small molecule were evaluated and no significant changes in the sensitivity were observed under manual optimization, thus, the capillary voltage of $3500 \mathrm{~V}$ was used. The data acquisition rate was also manually estimated using the dwell time function.

The main fragments of the deprotonated compounds is the loss of alkyl chain linked to the ester followed by the loss of $\mathrm{CO}_{2} \cdot{ }^{60}$ Thus, the nominated SRM transitions were $\left[\mathrm{M}-\mathrm{H}-\mathrm{CH}_{3}-\mathrm{CO}_{2}\right]^{-}$and $\left[\mathrm{M}-\mathrm{H}-\mathrm{CH}_{3}\right]^{-}$for methylparaben, $\left[\mathrm{M}-\mathrm{H}-\mathrm{CH}_{3}-\mathrm{CO}_{2}\right]^{-}$and $\left[\mathrm{M}-\mathrm{H}-\mathrm{CH}_{2}\right]^{-}$ for ethylparaben, $\left[\mathrm{M}-\mathrm{H}-\mathrm{CH}_{3}-\mathrm{CO}_{2}\right]^{-}$and $\left[\mathrm{M}-\mathrm{H}-\mathrm{CH}_{2}\right]^{-}$ for propylparaben and $\left[\mathrm{M}-\mathrm{H}-\mathrm{CH}_{3}-\mathrm{CO}_{2}\right]^{-}$and $\left[\mathrm{M}-\mathrm{H}-\mathrm{CH}_{3}\right]^{-}$for propylparaben.

As chromatographic conditions (step (ii)), isocratic elution using methanol $(\mathrm{MeOH})$ or acetonitrile $(\mathrm{ACN})$ as organic modifier in water were examined at the following proportions: 40:60, 50:50 and 70:30 but, they afforded high tail factors chromatographic bands when the SPE cartridge was coupled to the analytical column. The linear gradient elution mode (5 to $100 \% \mathrm{ACN}$ ) at $15 \%$ per min gradient step gave the highest resolution and minor tail factor and, thus, it was selected as the chromatographic conditions.

All selected parabens have approximately $\mathrm{p} K_{\mathrm{a}}$ of 8 and partition coefficient $(\log \mathrm{P})$ between 1.6-3.2. To improve ionization, experiments were carried out with and without additives such as: acetic and formic acid and ammonium formate in the mobile phase. No significant improvement in sensitivity for formic and acetic acid (less than 10\%) was observed, and with ammonium formate there was a decrease in signal intensity. Based on these results, and to avoid favoring the ionization of matrices interferents no additives were used. Flow rate at $0.4,0.5$ and $0.6 \mathrm{~mL} \mathrm{~min}^{-1}$ were also examined, and due to the ESI mass analyzer, the flow at $0.4 \mathrm{~mL} \mathrm{~min}^{-1}$ was selected.

For the final adjustment of the ionization source parameters (step (iii)) nebulizing flow, sheath, drying gas temperature and nitrogen flow parameters were all adjusted via the Source optimizer software. ${ }^{58}$ This might be done manually, but it is just much easier to use the software.

For the analysis cycle, parameters such as mobile phase for sample injection and SPE cartridges cleanups as well as SPE conditioning must be all evaluated (step (iv)). For selecting the appropriated conditions, one needs to consider the physicochemical characteristics of the SPE stationary phases. In this study, the polymeric-based SPE cartridge allowed the use of $\mathrm{MeOH}$ and $\mathrm{ACN}$ as organic modifiers. For sample cleanup, after injection, these modifiers in water at the proportion of 5 to $20 \%$ were examined. Due to the higher ACN elution strength, it affected the extraction of MP resulting in signal losses of at least $10 \%$ at total ion chromatogram (TIC). In this regard, $5 \%$ of $\mathrm{MeOH}$ in water was selected. For the SPE cartridge additional cleanup, $100 \% \mathrm{MeOH}$ was used, previously to conditioning at 5\% $\mathrm{MeOH}$ for the next injection. Since the analyses were carried out with $\mathrm{ACN}$ as mobile phase, the use of $\mathrm{MeOH}$ at the cleanup stage, resulted in higher selectivity.

To evaluate the cleanup time, the SPE cartridge was connected directly to the diode array detector (DAD) and the elution monitored at $254 \mathrm{~nm}$. The cleanup time was evaluated for the samples collected from four different locations from the urban waters in São Carlos-SP. The 1.75 min elution time using $5 \%$ of $\mathrm{MeOH}$ in water, at a flow rate of $1 \mathrm{~mL} \mathrm{~min}^{-1}$ accomplished the polar interferences removal. The use of a 10 port and 2 positions SPE valve allowed that while running the analysis, the second SPE cartridge to be cleaned/ conditioned for the following injection.

The analytical method was qualified following the EMA $^{59}$ validation guide and had the following parameters evaluated: memory effect, selectivity, calibration curve, precision and accuracy, recovery (extraction efficiency), limit of quantification and method detection, dilution integrity, stability and matrix effect. The SRM chromatogram of final method is illustrated in Figure 3.

The analytical calibration curve was plotted by linear regression in triplicate at six concentration level. The linear coefficient determination $\left(\mathrm{R}^{2}\right)$ was above 0.99 for all analytes, the RSD of the triplicates of the curve was lower than $10 \%$ showing suitability. The accuracy showed a deviation less than $15 \%$ of the nominal value in all concentrations of the curves, except for the LOQ of butylparaben where the deviation found was of $16 \%$ and some of these details are presented in Table 1 . The precision and accuracy of the method were evaluated through inter and intra-batch repeatability by low, medium and high concentration as quality control checks, and the results for accuracy and intermediate precision values obtained were $92-115 \%$ of the nominal value with RSD between $1.3-7.8 \%$, respectively.

The inter-batch accuracy and intermediate precision by two analysts in three different days still showed accuracy between $95-107 \%$ and RSD less than 10\%. The LOQ is the first concentration of the calibration curve with accuracy and precision that varied from $86-111 \%$ and $1-18 \%$ respectively, for the four parabens. For the LOD, verified 


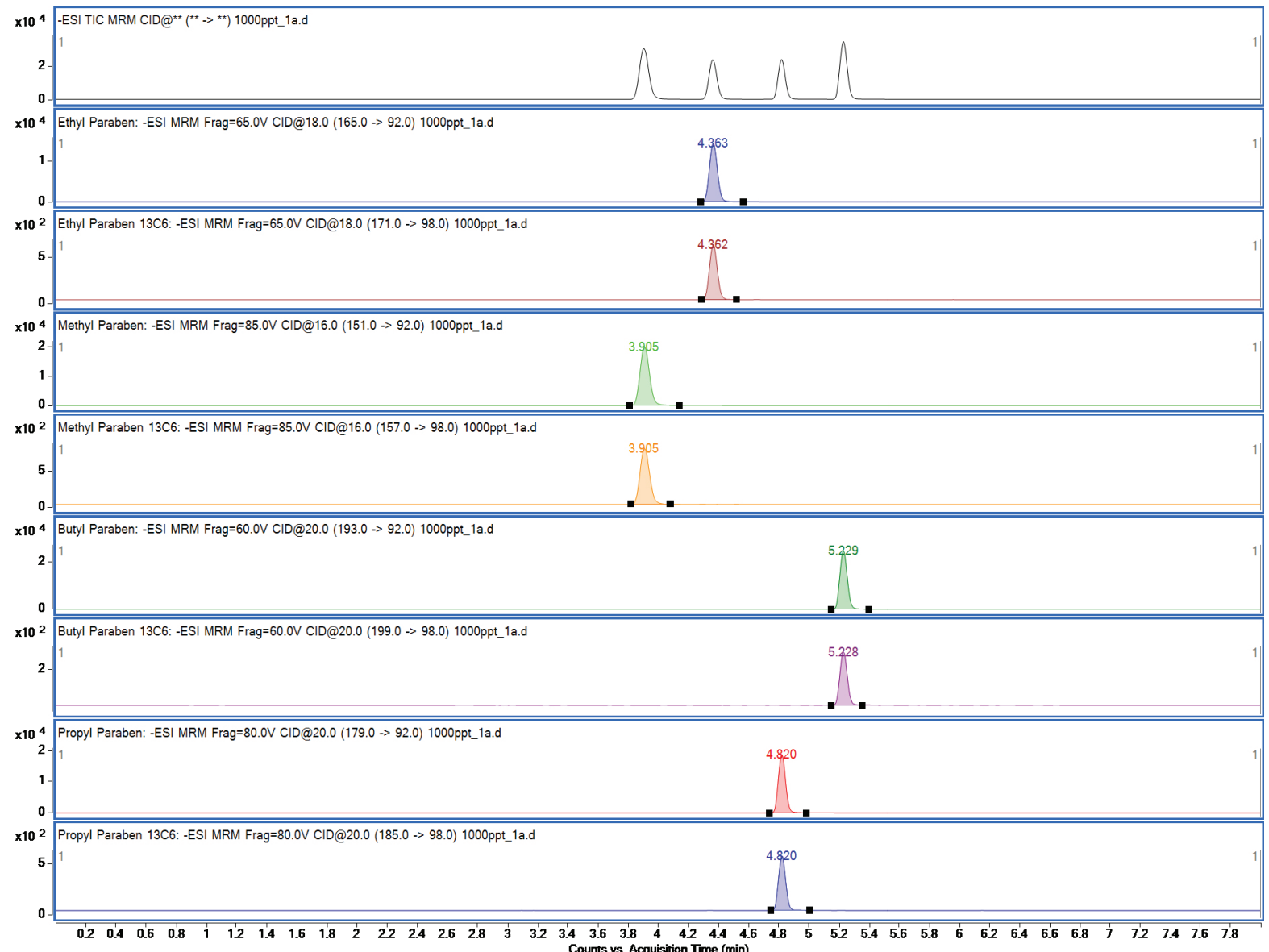

Figure 3. Final SRM chromatograms at $1,000 \mathrm{ng} \mathrm{L}^{-1}$ presented being the sequential of retention time methyl, ethyl, propyl and butyl parabens with their internal standard ${ }^{13} \mathrm{C}_{6}$.

Table 1. LOD (limit of detection), LOQ (limit of quantification), $\mathrm{R}^{2}$ (linear regression coefficient), equation of calibration curve and linear range are presented

\begin{tabular}{lccccc}
\hline Analyte & LOD / $\left(\mathrm{ng} \mathrm{L}^{-1}\right)$ & $\mathrm{LOQ} /\left(\mathrm{ng} \mathrm{L}^{-1}\right)$ & $\mathrm{R}^{2}$ & Calibration curve equation & Linear range / $\left.(\mathrm{ng} \mathrm{L})^{-1}\right)$ \\
\hline MP & 10.0 & 15.6 & 0.9981 & $y=0.025450 x+0.154160$ & $15.6-1000$ \\
EP & 15.6 & 31.2 & 0.9982 & $y=0.026428 x-0.134412$ & $31.2-1000$ \\
PP & 10.0 & 15.6 & 0.9976 & $y=0.033017 x+0.115954$ & $15.6-1000$ \\
BP & 2.0 & 3.9 & 0.9977 & $y=0.103970 x+0.253234$ & $3.9-1000$ \\
\hline
\end{tabular}

MP: methylparaben; EP: ethylparaben; PP: propylparaben; BP: butylparaben.

experimentally, the standard solution with the lowest reliable concentration that differed from the memory effect varied between 2.0-15.6 $\mathrm{ng} \mathrm{L}^{-1}$. The integrity of the dilution was given by diluting Monjolinho spring water 20 times in the concentration of 2,000 $\mathrm{ng} \mathrm{L}^{-1}$ (100 $\left.\mathrm{ng} \mathrm{L}^{-1}\right)$ in ultrapure water. The accuracy was $93-103 \%$ and the RSD was $3.8 \%$.

Stability assessment was carried out by comparing the average areas of the standards injected as soon as samples were prepared with 4 and $24 \mathrm{~h}$ in the auto injector and finally after 8 days of refrigeration. For that, the sample of urban water from site 4 at low and high concentrations was used since it was the most challenging matrix presenting the highest ionic suppression, these concentrations were evaluated in comparison to the standard solution of $125 \mathrm{ng} \mathrm{L}^{-1}$. Regarding stability, the first batch results were compared to 4 and $24 \mathrm{~h}$ after sample preparation, the accuracy values were between $88-106 \%$ and precision less than $15 \%$, showing satisfactory results up to $24 \mathrm{~h}$ period. Also, the results of the standard solution refrigerated for 8 days had an accuracy between 114-118\%, however, the sample analyzed in the same condition showed an accuracy of $12-20 \%$ for MP, $74-77 \%$ for EP, $202-210 \%$ for PP and $140-144 \%$ for BP. For the proposed condition, these results were considered unsatisfactory for sample storage period.

The method application was demonstrated applying it to samples of urban waters collected in the city of São 
Carlos-SP. The parabens quantifications in these samples showed the following results $<\mathrm{LOQ}$ (site 2), $20.0 \mathrm{ng} \mathrm{L}^{-1}$ of MP (site 3), $18.0 \mathrm{ng} \mathrm{L}^{-1}$ of MP and $4.1 \mathrm{ng} \mathrm{L}^{-1}$ of BP (site 4).

The use of IS was important for correcting the matrix effect of the samples from the collecting sites 2, 3 and 4 . Naturally, water presents different levels of humic and fulvic substances, scientific research ${ }^{61-64}$ has shown that extracting organic contaminants at a $\mathrm{pH}$ close to neutral limits influence the extraction of these interferents by SPE. Based on the chromatographic profile of humic substances standards compared to sample profiles obtained on DAD, as shown in Figures 4 and 5, it was obvious that the matrix effect was due to the amount of humic and fulvic acids in these samples. Although the method has determined conditions to minimize this effect, it was not possible to eliminate it as characteristics of the cartridge phase used for extraction and limitation of the configuration of online SPE. Without IS the results could had shown negative values based on ion suppression observed which was from $(-69.8)$ to $(-16.8)$. Nevertheless, due to useful use of IS, all urban waters exhibited precision within RSD below $15 \%$ and accuracy between $85-115 \%$.

The method was validated and met the acceptance criteria of the guide used. Matrix effect was observed due to the inefficiency of reduction of humic substances when present in high concentration in the samples. The use of the internal standard for each paraben, however, corrected the deviations caused by the matrix effect allowing $n g \mathrm{~L}^{-1}$ limits.
Comparison of this study results with countries such as China, ${ }^{65-67}$ India, ${ }^{7}$ Portugal,${ }^{68}$ Switzerland,,${ }^{8}$ UK $^{69}$ and other Brazilian ${ }^{16}$ reservoir was evaluated. Different samples cleanup procedures were described for the reported results varying from liquid-liquid extraction to offline and automated SPE for further analysis by GC-MS or LC-MS/MS. The parabens concentrations ranged from less than the LOQ up to $18,300 \mathrm{ng} \mathrm{L}^{-1}$ for methylparaben, $1,240 \mathrm{ng} \mathrm{L}^{-1}$ for ethylparaben, 5,940 $\mathrm{ng} \mathrm{L}^{-1}$ for propylparaben and $4,470 \mathrm{ng} \mathrm{L}^{-1}$ for butylparaben. The literature results highlight China and Switzerland as the countries from which highest concentrations for these parabens were found. The explanation for these results may be the high demographic density of the collected sites of the samples. The collection site in China ${ }^{65-67}$ was from a region of 12 million people, with only $70 \%$ of the treated sewage; Switzerland, ${ }^{7}$ although a region with a smaller number of residents, had collections in sites where only $10-21 \%$ of the sewage is treated and around 160 thousand people lives. A study ${ }^{16}$ reported $0.62 \mu \mathrm{g} \mathrm{L}^{-1}$ of MP from Lobo reservoir in Itirapina, São Paulo State a value much higher than the one found for urban water in this study and region. No quantification results were observed on South Wales rivers, UK, ${ }^{16,65}$ possibly because the lowest LOQ of their method was $0.2 \mu \mathrm{g} \mathrm{L} \mathrm{L}^{-1}$, over 65 times higher than that presented in our study and likewise their wastewater passed by activated sludge treatment that was reported with higher efficiency in the removal of parabens (> 99\% efficiency). ${ }^{16,65}$ Our finds

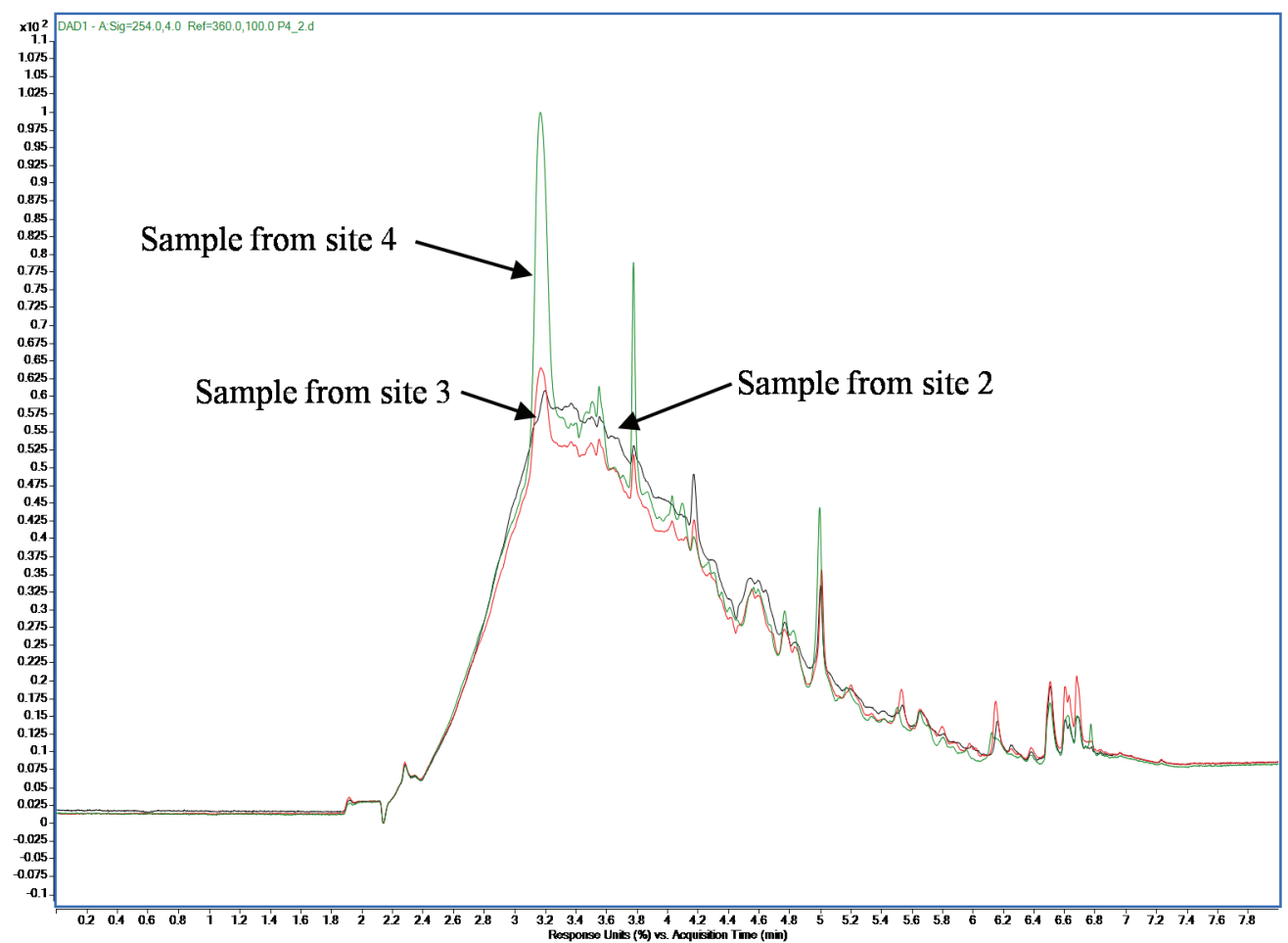

Figure 4. DAD signals at $254 \mathrm{~nm}$, being sample from site 2, 3 and 4 represented by the colors black, red and green, respectively. 


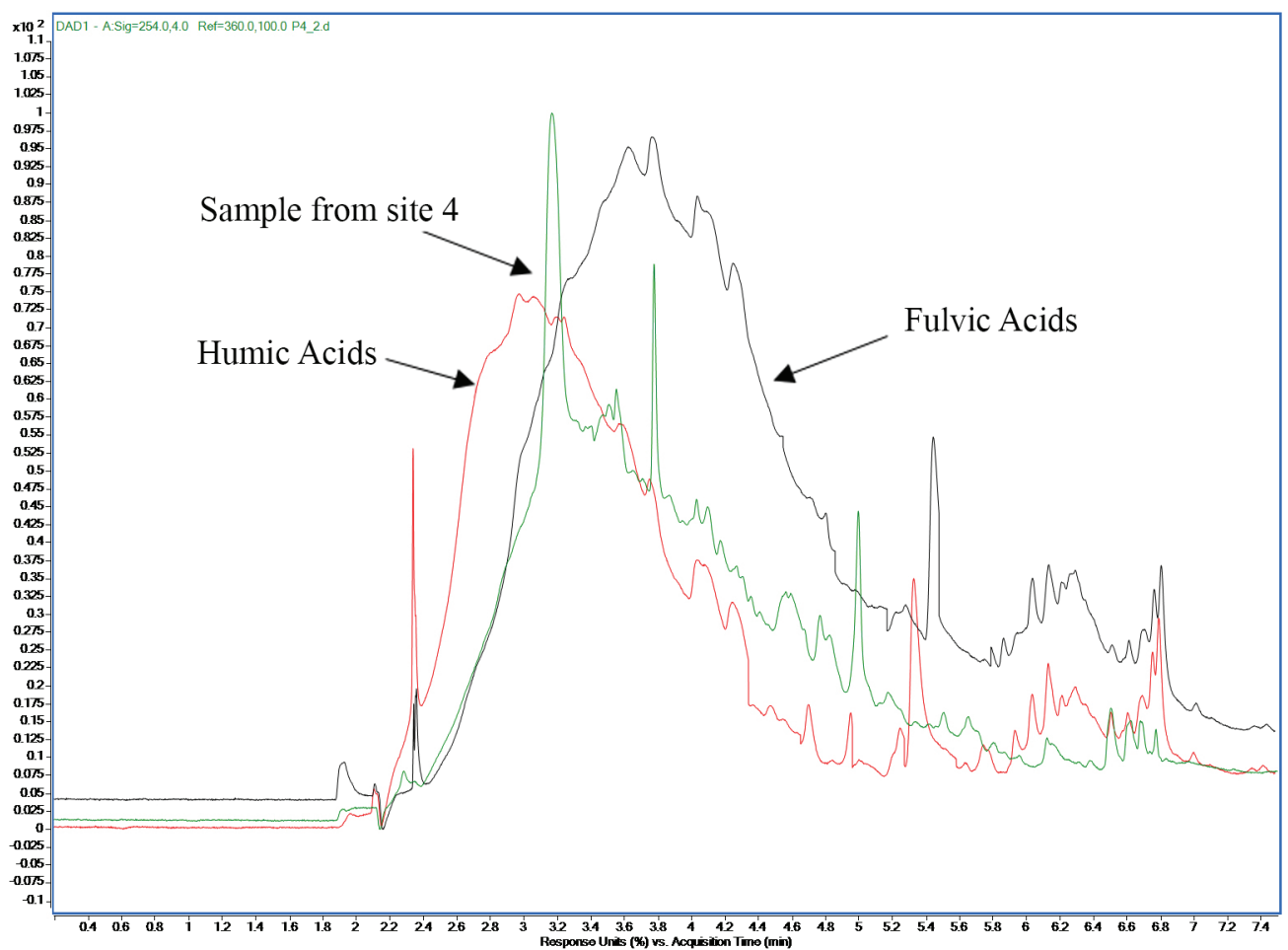

Figure 5. DAD signals at $254 \mathrm{~nm}$, being sample from site 4, humic and fulvic acids standards represented by the colors green, red and black, respectively.

showed positive results of MP at $20.0 \mathrm{ng} \mathrm{L}^{-1}$ in sample site 3, MP at $18.0 \mathrm{ng} \mathrm{L}^{-1}$ and $\mathrm{BP}$ at $4.1 \mathrm{ng} \mathrm{L}^{-1}$ in sample site 4 reporting closer results to Portugal ${ }^{68}$ that presented results of $17 \mathrm{ng} \mathrm{L}^{-1}$ for MP and $27 \mathrm{ng} \mathrm{L}^{-1}$ for PP.

\section{Conclusions}

Herein we report a method for quantification of methylparaben, ethylparaben, propylparaben and butylparaben in urban waters (São Carlos, SP, Brazil) by direct sample injection using a SPE-LC-MS/MS system. Quantification limits in the order of $\mathrm{ng} \mathrm{L}^{-1}$ with good accuracy and precision were achieved using internal standard for each paraben.

Methylparaben was found at collection sites 2, 3 and 4 with values from lower than LOQ up to $20.0 \mathrm{ng} \mathrm{L}^{-1}$. Butylparaben was found only at site 4 at $4.1 \mathrm{ng} \mathrm{L}^{-1}$.

The main features of the reported method are analysis run of 9.5 min including the cleanup cycles and columns conditioning, lower collection volumes of urban water and solvent usage. The SPE cartridge used showed robustness allowing over 500 sample injections ( $800 \mu \mathrm{L}$ each) with good chromatographic performance.

\section{Acknowledgments}

We acknowledge the Agency for the Improvement of Higher Education Personnel (CAPES) (finance code
001) for the financial support to the graduate program. The National Council for Scientific and Technological Development $(\mathrm{CNPq})$ is also acknowledged for the grant 3025557/2018-0. The equipment and technical support provided by Agilent Brazil is also acknowledged.

\section{References}

1. Garner, N.; Siol, A.; Eilks, I.; Chem. Action 2014, 103, 38, available at https://25593d2a-1813-4818-aca3-d56dd316e2c9. filesusr.com/ugd/7faa15_9e074968b5ee427a8cdca17b0a0a aa87.pdf, accessed in December 2020.

2. Yoom, H.; Shin, J.; Ra, J.; Son, H.; Ryu, D.; Kim, C.; Lee, Y.; Sci. Total Environ. 2018, 634, 677.

3. Saunders, L. J.; Mazumder, A.; Lowe, C. J.; Environ. Toxicol. Chem. 2016, 35, 919.

4. Daughton, C. G.; Ternes, T. A.; Environ. Health Perspect. 1999, 107, 907.

5. Błędzka, D.; Gromadzińska, J.; Wąsowicz, W.; Environ. Int. 2014, 67, 27.

6. Brausch, J. M.; Rand, G. M.; Chemosphere 2011, 82, 1518.

7. Ramaswamy, B. R.; Shanmugam, G.; Velu, G.; Rengarajan, B.; Larsson, D. G. J.; J. Hazard. Mater. 2011, 186, 1586.

8. Jonkers, N.; Kohler, H. P. E.; Dammshäuser, A.; Giger, W.; Environ. Pollut. 2009, 157, 714.

9. Kang, S.; Kim, S.; Park, J.; Kim, H. J.; Lee, J.; Choi, G.; Choi, S.; Kim, S.; Kim, S. Y.; Moon, H. B.; Kim, S.; Kho, Y. L.; Choi, K.; Sci. Total Environ. 2013, 461-462, 214. 
10. Cabaleiro, N.; De la Calle, I.; Bendicho, C.; Lavilla, I.; TrAC, Trends Anal. Chem. 2014, 57, 34.

11. Li, X. J.; Tang, X.; Zhou, X. H.; Chen, M. S.; Dai, J. L.; Xiong, W. M.; Zou, Z. X.; Liu, H. J.; Lv, S. Y.; Lin, H.; Lian, M.; Appl. Mech. Mater. 2013, 333-335, 1993.

12. Terasaki, M.; Takemura, Y.; Makino, M.; Environ. Chem. Lett. 2012, 10, 401.

13. Madureira, T. V.; Barreiro, J. C.; Rocha, M. J.; Cass, Q. B.; Tiritan, M. E.; J. Chromatogr. A 2009, 1216, 7033.

14. Zhang, D.; Gersberg, R. M.; Ng, W. J.; Tan, S. K.; Environ. Pollut. 2014, 184, 620.

15. Soni, M. G.; Carabin, I. G.; Burdock, G. A.; Food Chem. Toxicol. 2005, 43, 985 .

16. Pompei, C. M. E.; Campos, L. C.; da Silva, B. F.; Fogo, J. C.; Vieira, E. M.; Chemosphere 2019, 226, 210.

17. Marta-Sanchez, A. V.; Caldas, S. S.; Schneider, A.; Cardoso, S. M. V. S.; Primel, E. G.; Environ. Sci. Pollut. Res. 2018, 25, 14460.

18. Chen, Y.; Deng, P.; Xie, P.; Shang, R.; Wang, Z.; Wang, S.; Chemosphere 2017, 168, 1628.

19. Kang, H. M.; Kim, M. S.; Hwang, U. K.; Jeong, C. B.; Lee, J. S.; Chemosphere 2019, 226, 388.

20. Ribeiro, C.; Ribeiro, A. R.; Maia, A. S.; Gonçalves, V. M. F.; Tiritan, M. E.; Crit. Rev. Anal. Chem. 2014, 44, 142.

21. Caban, M.; Lis, E.; Kumirska, J.; Stepnowski, P.; Sci. Total Environ. 2015, 538, 402.

22. Liu, Z.-h; Lu, G.-n; Yin, H.; Dang, Z.; Littier, H.; Liu, Y.; TrAC, Trends Anal. Chem. 2015, 64, 149.

23. Hodgeson, J. W.; Collins, J.; Barth, R. E.; Method 552: Determination of Haloacetic Acids in Drinking Water by LiquidLiquid Extraction, Derivatization, and Gas Chromatography with Electron Capture Detection; Environmental Monitoring Systems Laboratory Office of Research and Development U.S. Environmental Protection Agency: Cincinnati, Ohio, 1990, available at https://www.o2si.com/docs/epa-method-552.pdf, accessed in December 2020.

24. Munch, J. W.; Method 525.2: Determination of Organic Compounds in Drinking Water by Liquid-Solid Extraction and Capillary Column Gas Chromatography/Mass Spectrometry; Environmental Monitoring Systems Laboratory Office of Research and Development U.S. Environmental Protection Agency: Cincinnati, Ohio, 1995, available at https://www.epa. gov/sites/production/files/2015-06/documents/epa-551.1.pdf, accessed in December 2020.

25. Munch, J. W.; Hautman, D. P.; Method 551.1: Determination of Chlorination Disinfection Byproducts, Chlorinated Solvents, and Halogenated Pesticides/Herbicides in Drinking Water by Liquid-Liquid Extraction and Gas Chromatography with Electron-Capture Detection; Environmental Monitoring Systems Laboratory Office of Research and Development U.S. Environmental Protection Agency: Cincinnati, Ohio, 1995, available at https://www.epa.gov/sites/production/files/2015-06/ documents/epa-525.2.pdf, accessed in December 2020.

26. Munch, J. W.; Method 515.2: Determination of Chlorinated Acids in Water Using Liquid-Solid Extraction and Gas Chromatography with an Electron Capture Detector; Environmental Monitoring Systems Laboratory Office of Research and Development U.S. Environmental Protection Agency: Cincinnati, Ohio, 1995, available at https://www.o2si. com/docs/epa-method-515.2.pdf, accessed in December 2020.

27. Munch, J. W.; Method 508: Determination of Chlorinated Pesticides in Water by Gas Chromatography with An Electron Capture Detector; Environmental Monitoring Systems Laboratory Office of Research and Development U.S. Environmental Protection Agency: Cincinnati, Ohio, 1995, available at https://www.o2si.com/docs/epa-method-508.pdf, accessed in December 2020.

28. Munch, J. W.; Method 506: Determination of Phthalate and Adipate Esters in Drinking Water by Liquid-Liquid Extraction or Liquid-Solid Extraction and Gas Chromatography with Photoionization Detection; Environmental Monitoring Systems Laboratory Office of Research and Development U.S. Environmental Protection Agency: Cincinnati, Ohio, 1995, available at http://www.cromlab.es/Articulos/Metodos/ EPA/500/506.pdf, accessed in December 2020.

29. Majors, E. R. In Sample Preparation Fundamentals for Chromatography; Agilent: Delaware, USA, 2013, available at https://www.agilent.com/cs/library/primers/Public/59913326EN_SPHB.pdf, accessed in December 2020.

30. Raynie, E. D.; LCGC North America 2016, 34, 174, available at https://www.chromatographyonline.com/view/trends-samplepreparation-4, accessed in December 2020.

31. Chirila, E. S.; Draghici, C.; Dobrinas, S. In Chemicals as Intentional and Accidental Global Environmental Threats; Simeonov, L.; Chirila, E. eds.; Springer: Brasov, 2006, p. 7.

32. Petrovic, M.; Farré, M.; de Alda, M. L.; Perez, S.; Postigo, C.; Köck, M.; Radjenovic, J.; Gros, M.; Barcelo, D.; J. Chromatogr. A 2010, 1217, 4004.

33. Ramos, L.; J. Chromatogr. A 2012, 1221, 84.

34. Poole, C. F.; Gunatilleka, A. D.; Sethuraman, R.; J. Chromatogr. A 2000, 885, 17.

35. Hennio, M.-C.; J. Chromatogr. A 1999, 856, 3.

36. Gilart, N.; Borrull, F.; Fontanals, N.; Marcé, R. M.; Trends Environ. Anal. Chem. 2014, 1, e8.

37. Fumes, B. H.; Silva, M. R.; Andrade, F. N.; Nazario, C. E. D.; Lanças, F. M.; TrAC, Trends Anal. Chem. 2015, 71, 9.

38. Poole, C. F.; TrAC, Trends Anal. Chem. 2003, 22, 362.

39. Barreiro, J. C.; Vanzolini, K. L.; Madureira, T. V.; Tiritan, M. E.; Cass, Q. B.; Talanta 2010, 82, 384.

40. Valls-Cantenys, C.; Scheurer, M.; Iglesias, M.; Sacher, F.; Brauch, H. J.; Salvadó, V.; Anal. Bioanal. Chem. 2016, 408, 6189.

41. Cerqueira, M. B. R.; Caldas, S. S.; Primel, E. G.; J. Chromatogr. A 2014, 1336, 10. 
42. Bylda, C.; Thiele, R.; Kobold, U.; Volmer, D. A; Analyst 2014, 139, 2265.

43. Lopes, B. R.; Barreiro, J. C.; Cass, Q. B.; J. Pharm. Biomed. Anal. 2016, 130, 318.

44. Barciela-Alonso, M. C.; Otero-Lavandeira, N.; BermejoBarrera, P.; Microchem. J. 2017, 132, 233.

45. Cassiano, N. M.; Barreiro, J. C.; Cass, Q. B.; J. Braz. Chem. Soc. 2014, 25, 9.

46. Munch, J. W.; Method 528: Determination of Phenols in Drinking Water by Solid Phase Extraction and Capillary Column Gas Chromatography/Mass Spectrometry (GC/MS); Environmental Monitoring Systems Laboratory Office of Research and Development U.S. Environmental Protection Agency: Cincinnati, Ohio, 2000, available at https://www.epa. gov/sites/production/files/2015-09/documents/m_528.pdf, accessed in December 2020.

47. Moghimi, A.; Hosseini, S. A.; Far, A. M.; Orient. J. Chem. 2015, $31,263$.

48. Gołębiowski, M.; Stepnowski, P.; Leszczyńska, D.; Chem. Pap. 2017, 71, 831.

49. Buszewski, B.; Szultka, M.; Crit. Rev. Anal. Chem. 2012, 42, 198.

50. Liska, I.; J. Chromatogr. A 1993, 655, 163.

51. Tlili, I.; Caria, G.; Ouddane, B.; Ghorbel-Abid, I.; Ternane, R.; Trabelsi-Ayadi, M.; Net, S.; Sci. Total Environ. 2016, 563-564, 424.

52. Kuklenyik, Z.; Calafat, A. M.; Barr, J. R.; Pirkle, J. L.; J. Sep. Sci. 2011, 34, 3606.

53. Heuett, N. V.; Ramirez, C. E.; Fernandez, A.; Gardinali, P. R.; Sci. Total Environ. 2015, 511, 319.

54. Fernández-Ramos, C.; Šatínský, D.; Solich, P.; Talanta 2014, $129,579$.
55. García-Galán, M. J.; Díaz-Cruz, M. S.; Barceló, D.; Talanta 2010, 81, 355.

56. Bones, J.; Thomas, K.; Nesterenko, P. N.; Paull, B.; Talanta 2006, 70, 1117.

57. Cass, Q. B.; Cassiano, N. M. In Cromatografia Líquida: Novas Tendências e Aplicações; Elsevier: Rio de Janeiro, Brazil, 2015.

58. MassHunter Optimizer, version B07; Agilent Inc., Santa Clara, CA, USA, 2014.

59. Smith, G.; Bioanalysis 2012, 4, 865.

60. González-Mariño, I.; Quintana, J. B.; Rodríguez, I.; Cela, R. S.; Rapid Commun. Mass Spectrom. 2009, 23, 1756.

61. Carder, K. L.; Steward, R. G.; Harvey, G. R.; Ortner, P. B.; Limnol. Oceanogr. 1989, 34, 68.

62. Weigel, S.; Kallenborn, R.; Hühnerfuss, H.; J. Chromatogr. A 2004, 1023, 183.

63. Guenu, S.; Hennion, M. C.; J. Chromatogr. A 1996, 737, 15.

64. Lin, W. C.; Chen, H. C.; Ding, W. H.; J. Chromatogr. A 2005 , 1065, 279.

65. Huang, C.; Wu, L. H.; Liu, G. Q.; Shi, L.; Guo, Y.; Arch. Environ. Contam. Toxicol. 2018, 75, 224.

66. Lu, J.; Mao, H.; Li, H.; Wang, Q.; Yang, Z.; Sci. Total Environ. 2017, 605-606, 1064.

67. Peng, X.; Yu, Y.; Tang, C.; Tan, J.; Huang, Q.; Wang, Z.; Sci. Total Environ. 2008, 397, 158.

68. Jonkers, N.; Sousa, A.; Galante-Oliveira, S.; Barroso, C. M.; Kohler, H. P. E.; Giger, W.; Environ. Sci. Pollut. Res. 2010, 17, 834.

69. Kasprzyk-Hordern, B.; Dinsdale, R. M.; Guwy, A. J.; Water Res. 2009, 43, 363.

Submitted: September 8, 2020 Published online: December 21, 2020 